\title{
The Australasian muricid gastropod Lepsiella as Pleistocene visitor to southernmost South America
}

Sandra Gordillo and Sven N. Nielsen

Acta Palaeontologica Polonica 58 (4), 2013: 777-783 doi: http://dx.doi.org/10.4202/app.2011.0186

Six shells belonging to a muricid gastropod species were recovered from a Pleistocene marine raised beach located on Navarino Island, in southern South America. None of the living species in the Beagle Channel or in the area is close, and none of the fossil species in the vicinity regions shows the diagnostic characters of the Navarino Pleistocene fossils. Our material resembles Lepsiella baileyana from southern Australia, although some differences in the suture and in the spire outline are recognized. Haustrinae were previously confined geographically to New Zealand and to the temperate coast of Australia, now extending its range of distribution to southern South America. This finding of Lepsiella ukika sp. nov. is best explained on the basis of transoceanic migration from Australasia by means of the Antarctic Circumpolar Current perhaps during a Quaternary glacial period. The presence of this Pleistocene visitor in southern South America is important because it clearly demonstrates that transcontinental traverse of taxa with direct (non-planktonic) development might have happened by rafting on kelp that served as transport platforms.

Key words: Gastropoda, Muricidae, Pleistocene, Beagle Channel, Australasia connection.

Sandra Gordillo [sgordillo@cicterra-conicet.gov.ar], Centro de Investigaciones en Ciencias de la Tierra, Consejo Nacional de Investigaciones Científicas y Técnicas (CICTERRA, CONICET) and Centro de Investigaciones Paleobiológicas (CIPAL), Facultad de Ciencias Exactas, Físicas y Naturales, Universidad Nacional de Córdoba, Av. Vélez Sársfield 1611 X5016GCA Córdoba, Argentina; Sven N. Nielsen [sven.nielsen@uach.cl], Institut für Geowissenschaften, Christian-Albrechts-Universität zu Kiel. Ludewig-Meyn-Str. 10, 24118 Kiel, Germany; current address: Instituto de Ciencias Ambientales y Evolutivas Universidad Austral de Chile, Casilla 567, Valdivia, Chile.

This is an open-access article distributed under the terms of the Creative Commons Attribution License (for details please see creativecommons.org), which permits unrestricted use, 
distribution, and reproduction in any medium, provided the original author and source are credited.

Fof Full text $(289.6 \mathrm{kB})$ 